\title{
EVALUATION OF FAULT DETECTION TECHNIQUES USED FOR INDUCTION MOTOR WITH STATOR WINDING TURN FAULT
}

\author{
M. Alaam M. Abdel-Kariem M. A. El-Khazendar \\ Electrical Power and Machines Department, Faculty of Engineering \\ Tanta University, Egypt
}

\begin{abstract}
In this paper, a comparative study among various fault detection techniques used for induction motors with stator winding turn fault is presented. In these techniques the three-phase voltage and current waveforms at the terminal of the motor are used to extract the fault signature. This study is based on simulating the faulty motor on phase $(a b c)$ frame. The effect of load, fault resistance, and fault location "faulty turns percentage" on the accuracy of fault detector determination are investigated. Also, the imperfections existed in motor and voltage source unbalance are studied and corrected to cancel their effects on fault signature. Applicability of each of the techniques to on-line use is examined. The results revealed the most appropriate technique among the compared fault detection techniques.

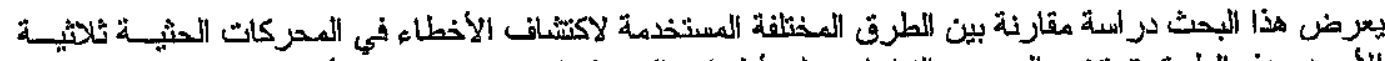

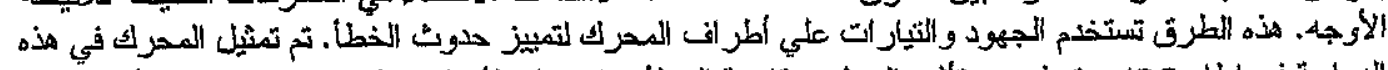

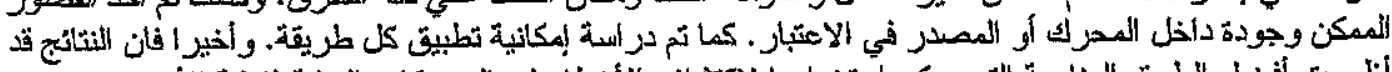

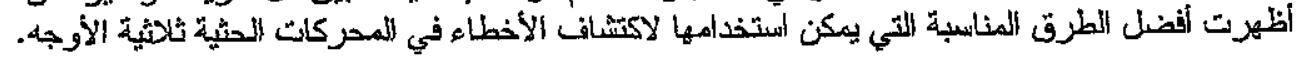

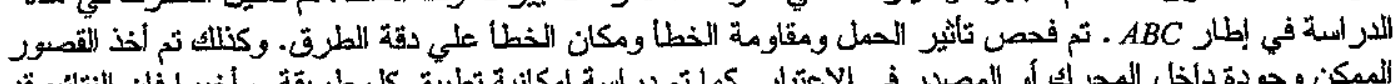

\section{INTRODUCTION}

Three-phase squirrel cage induction motors form the backbone of a substantial portion of the adjustable speed drives applications. Being structurally robust and cheap, they are the primary source of motive power and speed control where dc and synchronous motors cannot be used (for high speed and high voltage applications). An unscheduled shutdown occurs if only one of these motors fails. If it was possible to detect a developing fault at its incipient instant, it is possible to schedule an orderly shutdown of the complete process. In these cases, it can be cost effective to continuously monitor the above mentioned electric motors. Nevertheless, the defective motor will need to be exchanged and repaired. Researchers have studied a variety of motor faults as winding faults, stator and rotor unbalances, broken rotor bars, eccentricity, and bearing fault [13]. Several studies have shown that $30 \%: 40 \%$ of induction motor failure are due to stator winding breakdown [1], [4].

Fault detection techniques used for induction motors with stator winding turn fault can be classified into off-line techniques [5-7], and on-line techniques [810]. On-line techniques depending on only voltage and current waveforms are desirable and appropriate techniques. In this paper, a comparative study among the most fault detection techniques in literatures is presented. The comparison is carried out from the view point of accuracy, speed in determining the fault occurring and the ability of removing the effects of external disturbances. The effects of load, percentage of fault turns and the imperfections in motor on the performance of detector are investigated. The study is carried out on the samples of voltage and current resulted from induction motor simulated in phase $(a b c)$ frame.

This paper first presents a simulation for induction motor with stator winding turn fault in $a b c$ frame [11]. Later sections explain and compare among the choosing techniques. This paper finally presents a conclusion aid the field engineers to evaluate and select the most appropriate and accurate method for their own application.

\section{INDUCTION MOTOR WITH STATOR WINDING TURN FAULT SIMULATION}

The equations which describe the induction motor with stator winding turn fault can be written in vector/matrix form as follows:

$\left[V_{s}\right]=\left[R_{s}\right]\left[I_{s}\right]+\frac{d\left[\psi_{s}\right]}{d t}$
$\left[V_{r}\right]=\left[R_{r}\right]\left[I_{r}\right]+\frac{d\left[\psi_{r}\right]}{d t}$
$\left[\psi_{s}\right]=\left[L_{l s}+M_{s s}\right]\left[I_{s}\right]+\left[M_{s r}\right]\left[I_{r}\right]$
$\left[\psi_{r}\right]=\left[M_{r s}\right]\left[I_{s}\right]+\left[L_{l r}+M_{r r}\right]\left[I_{r}\right]$

where, for a squirrel-cage induction motor, $\left[V_{r}\right]=[0]$ and $\left[M_{r s}\right]=\left[M_{s r}\right]^{T}$ and 


$$
\left[V_{s}\right]=\left[\begin{array}{c}
v_{a s} \\
v_{b s} \\
v_{c s}
\end{array}\right], \quad\left[I_{s}\right]=\left[\begin{array}{l}
i_{a s} \\
i_{b s} \\
i_{c s}
\end{array}\right] \quad\left[I_{r}\right]=\left[\begin{array}{c}
i_{a r} \\
i_{b r} \\
i_{c r}
\end{array}\right]
$$

are the stator voitage vector, stator current vector, and rotor current vector, respectively.

For the rotor circuits, the mutual inductance matrix $\left[M_{r r}\right]$, the resistance matrix $\left[R_{r}\right]$, and the leakage inductance matrix $\left[L_{l r}\right]$ are not influenced by the stator faults. These parameters can be written as follows:

$$
\begin{gathered}
{\left[M_{r r}\right]=\left[\begin{array}{ccc}
M & -0.5 M & -0.5 M \\
-0.5 M & M & -0.5 M \\
-0.5 M & -0.5 M & M
\end{array}\right]} \\
{\left[R_{r}\right]=\left[\begin{array}{lll}
r_{r} & 0 & 0 \\
0 & r_{r} & 0 \\
0 & 0 & r_{r}
\end{array}\right]\left[L_{l r}\right]=\left[\begin{array}{ccc}
L_{l r} & 0 & 0 \\
0 & L_{l r} & 0 \\
0 & 0 & L_{l r}
\end{array}\right]}
\end{gathered}
$$

Clearly, the stator faults have a direct influence on the stator parameters (resistances, leakage inductances, and mutual inductances between phases) and on the mutual inductances between the stator and the rotor $\left(\left[M_{s r}\right]\right.$ and $\left.\left[M_{r s}\right]\right)$.

By taking the expression of each parameter in function of the number of windings in each turn, considering the percentage of turn faulted $\mu_{\mathrm{as}}, \mu_{\mathrm{ts}}$ and $\mu_{\mathrm{cs}}$, for phases $\mathrm{a}, \mathrm{b}$, and c respectively, while $\mu_{\mathrm{as}}$, $\mu_{\mathrm{bs}}{ }^{*}$ and $\mu_{\mathrm{cs}}$, are the percentage of turns unfaulted (i.e. healthy portion) for phases $a, b$, and $c$ respectively, the stator parameter matrices can be written as [11];

$$
\begin{aligned}
& {[R]=\left[\begin{array}{ccc}
\mu_{a s}^{*} r_{s} & 0 & 0 \\
0 & \mu_{s}^{*} r_{s} & 0 \\
0 & 0 & \mu_{c s}^{*} r_{s}
\end{array}\right] \quad\left[L_{s s}\right]=\left[\begin{array}{ccc}
\mu_{b s}^{2} L_{s} & 0 & 0 \\
0 & \mu_{b s}^{*} L_{s} & 0 \\
0 & 0 & \mu_{c s}^{2} L_{s}
\end{array}\right]} \\
& {\left[M_{s s}\right]=\left[\begin{array}{ccc}
\mu_{c s}^{*} M & -\mu_{a s}^{*} \mu_{b s}^{*} \frac{M}{2} & -\mu_{a s}^{*} \mu_{c s}^{*} \frac{M}{2} \\
-\mu_{b s}^{*} \mu_{a s}^{*} \frac{M}{2} & \mu_{b s}^{* 2} M & -\mu_{b s}^{*} \mu_{c s}^{*} \frac{M}{2} \\
-\mu_{c s}^{*} \mu_{a s}^{*} \frac{M}{2} & -\mu_{c s}^{*} \mu_{b s}^{*} \frac{M}{2} & \mu_{c s}^{*} M
\end{array}\right]}
\end{aligned}
$$

Using $\theta_{r}$, the angle between stator phase and rotor phase, the mutual inductance matrices $\left[M_{s r}\right]$ and $\left[M_{r s}\right]$ are

$$
\left[M_{s r}\right]=\left[\begin{array}{lll}
\mu_{a s}^{*} M c_{1} & \mu_{a s}^{*} M c_{2} & \mu_{a s}^{*} M c_{3} \\
\mu_{b s}^{*} M c_{2} & \mu_{b s}^{*} M c_{3} & \mu_{b s}^{*} M c_{1} \\
\mu_{c s}^{*} M c_{3} & \mu_{c s}^{*} M c_{2} & \mu_{c s}^{*} M c_{1}
\end{array}\right]=\left[M_{r s}\right]^{T}
$$

where

$$
c_{1}=\cos \left(\theta_{r}\right), c_{2}=\cos \left(\theta_{r}-\frac{2}{3} \pi\right) \text { and } c_{3}=\cos \left(\theta_{r}+\frac{2}{3} \pi\right)
$$

The equations describing the mechanical part of the motor are:

$$
T_{c}=\left[I_{s}\right]^{T} \frac{\partial\left[M_{s r}\right]}{\partial \theta}\left[I_{r}\right]
$$

$\frac{d \omega_{r}}{d t}=\frac{P}{2 J}\left(T_{e}-T_{l}\right)$

$\theta_{r}=\int \omega_{r} d t$

where, $T_{e}$ is the electromagnetic torque, $T_{l}$ is load torque, $\omega_{r}$ is the angular mechanical speed, $J$ is the combined rotor-load inertia, $P$ is the number of motor poles, and $\theta_{r}$ is the mechanical angle. Parameters of the example motor in its ideal version are attached in Appendix.

A signal processing algorithm is used to estimate the voltage and current phasors from the samples of waveforms. The signal processing algorithm is based on recursive discrete Fourier transform DFT [12]. Using the estimated phasor quantities, the fault signature can be extracted and fault detection can be estimated.

Figure. 1. illustrates the current waveform of phase $A$ for $5 \%$ of turns in phase $A$ short-circuited. Figure. 2 depicts the estimated amplitude of the fundamental frequency component of the phase $A$ current for the previous described fault.

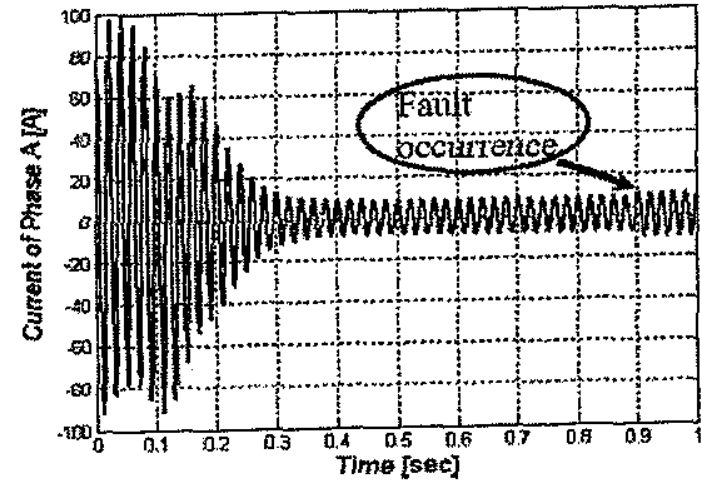

Fig. 1. The current waveform of phase $A$ for $5 \%$ of turns in phase $A$ short-circuited

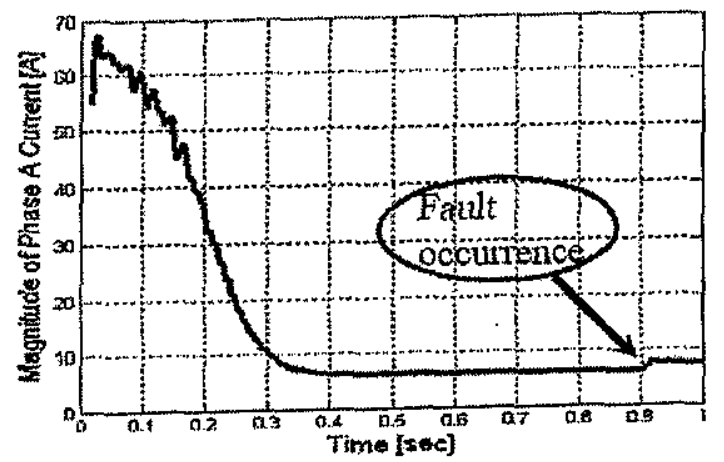

Fig. 2. The estimated amplitude of the fundamental frequency component of the phase $A$ current for $5 \%$ of turns in phase $A$ short-circuited 


\section{STATOR WINDING TURN FAULT DETECTION TECENIQUES}

Several fault detection techniques have been reported. Five of the most applicable among these techniques are described and examined here. Also, a neural network based method is proposed at the end of this paper.

\subsection{Standard Deviation of Line Current Technique}

Let $I_{a}, I_{b}$, and $I_{c}$ be the RMS values of three-phase currents drawn by the motor. When the motor is known to be in a healthy state, the three RMS values, $I_{a}^{h}, I_{b}^{t}$, and $I_{c}^{h}$ are acquired, stored, and referenced for the relative balance of the motor. Then, $I_{a}, I_{b}$, and $I_{c}$ may be scaled according to $I_{a}^{h}, l_{b}^{h}$, and $I_{c}^{h}$ to normalize each phase current, at that time, and under that particular load, to one per-unit. That is

$\frac{I_{a}}{I_{a}^{h}}=\frac{I_{b}}{I_{b}^{h}}=\frac{I_{c}}{I_{c}^{h}}=1.0$

Then, assuming the balance of the source is consistent, the balance in the "normalized" currents will persist. A change in motor load will change the value of the phase currents and then the above ratio will not equal to 1.0. However, that difficuity is eliminated by also scaling the monitored currents at the reference condition, to the average of the currents at the present, monitored condition. The combination of these scaling factors for the three-phase currents yields three ratios, each having the form of [8]:

$\alpha_{a}=\frac{I_{a v e}^{h}}{l_{a}^{h} I_{a v e}}$

where

$I_{\mathrm{avc}}^{\mathrm{h}}=\frac{I_{a}^{h}+I_{b}^{h}+I_{c}^{h}}{3}$

and

$I_{a v e}=\frac{I_{a}+I_{b}+I_{c}}{3}$

Thus, the scaling factor for each RMS phase current becomes of the form:

$\alpha_{a}=\frac{\left(I_{a}^{h}+I_{b}^{h}+I_{c}^{h}\right)}{I_{a}^{h}\left(I_{a}+I_{b}+I_{c}\right)}$

Then, the balance between the phasors may be determined through the standard deviation of the three, calibrated line RMS currents $\sigma$ on a continual basis, and compared to a user selected threshold value, $\delta$ :

$\sigma=\sqrt{\sum_{m=a, b, c}\left(\alpha_{m} I_{m}-1\right)^{2}}$
The choice to scale the RMS currents as explained will permit the user to select a convenient choice of $\delta$ that already accounts for known dependencies and inherent imbalances. The value of the threshold $\delta$ would be set dependent upon many factors, including experience, measurement error and fault tolerance.

Figure. 3. illustrates the change of $\sigma$ due to fault occurring on $1 \%, 5 \%$, and $10 \%$ of winding turns in phase $A$. Figure. 4. revealed the relation of $\sigma$ and percentage of turn faulted and motor load. Figure. 5 . shows the change of $\sigma$ due to $1 \%$ unbalance in voltage supply occurring at $0.92 \mathrm{sec}$.

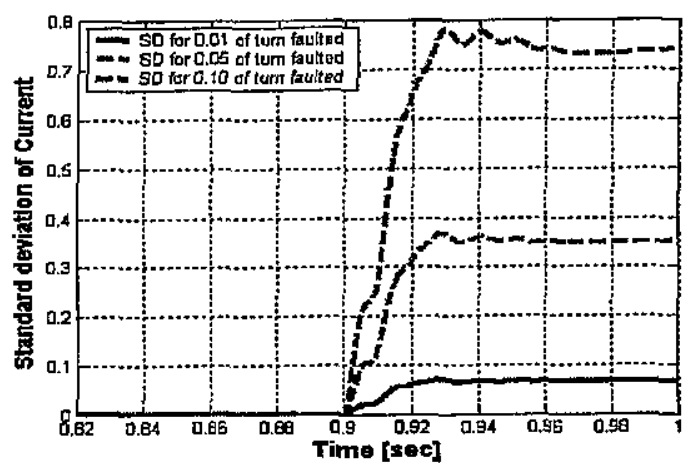

Fig. 3. The change of $\sigma$ due to fault occurring on $1 \%$, $5 \%$, and $10 \%$ of winding turns in phase $A$

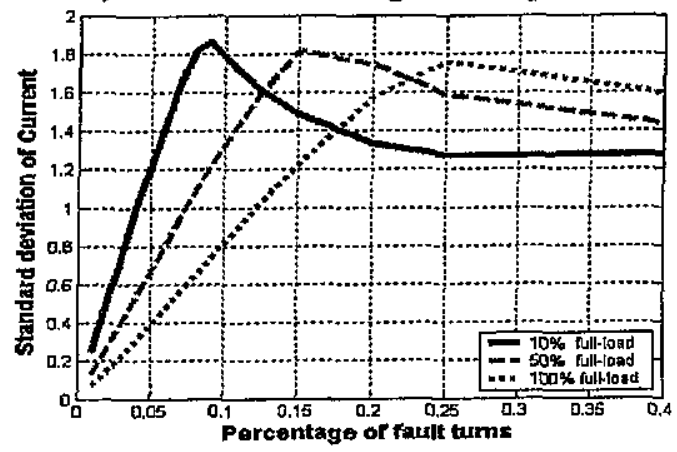

Fig. 4. The effect of tum faulted percentage and motor load on $\sigma$

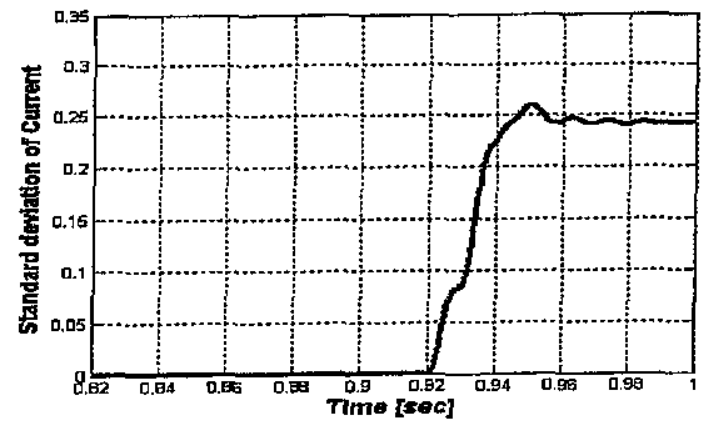

Fig. 5. Voltage supply unbalance effect on $\sigma$

Figure. 5. revealed that, the change in the balance of the phase currents depend upon balance in the source, this technique is not intended for mains-connected motors "direct-on-line motors", because nearby voltage unbalance might cause fault alarms. 


\subsection{Extended Park's Vector Approach (EPVA)}

This method consists of decomposing the three time varying phase current values into their associated "direct" and "quadrature" components. Which are given by:

$\left[\begin{array}{l}i_{d} \\ i_{q} \\ i_{0}\end{array}\right]=\left[\begin{array}{ccc}\sqrt{2 / 3} & -\sqrt{1 / 6} & -\sqrt{1 / 6} \\ 0 & \sqrt{1 / 2} & -\sqrt{1 / 2} \\ \sqrt{1 / 3} & \sqrt{1 / 3} & \sqrt{1 / 3}\end{array}\right]\left[\begin{array}{l}i_{a s} \\ i_{b s} \\ i_{c s}\end{array}\right]$

while concurrently plotting the two waveforms, $i_{d}$ and $i_{q}$ in an $\mathrm{X}-\mathrm{Y}$ display over time. Turn faults, or other gross motor anomalies will cause such a plot to deviate in size, shape or clarity from their normal figures. In the ideal case where the phase current are perfectly balanced, $i_{d}$ and $i_{q}$ reduce to sinusoids of the same magnitude and $90^{\circ}$ phase difference, thus producing a sharp circle in X-Y display.

Proponents of this methods are few, because of its handicaps. First, this method fails to incorporate supply deviations, which can affect the results as much as motor problems can. Second, cyclic or random loads on the motor (as in a compressor) can make comparisons difficult and fault detection near impossible.

To avoid this problem, let $i_{d}$ and $i_{q}$ are components of a vector called Park's vector, then determine the spectral analysis for this vector. The amplitude of this vector at twice the fundamental frequency is calculated. The ratio between the amplitude of the Park's vector at a frequency of $2 f_{l}$ and a dc level of the vector is known as a severity factor. This factor is used as a good indicator for the presence of turn fault.

The motor was tested with several numbers of shortcircuited turns. Figure. 6 shows the Park's vector waveform for the case of $1 \%, 5 \%$ and $10 \%$ shortcircuited turns. Figure. 7 illustrates the severity factor for the mentioned fault cases.

It should be noted that the amplitude increases with the extension of the fault. Figure. 8 illustrates the evaluation of the severity factor with the number of shorted turns.

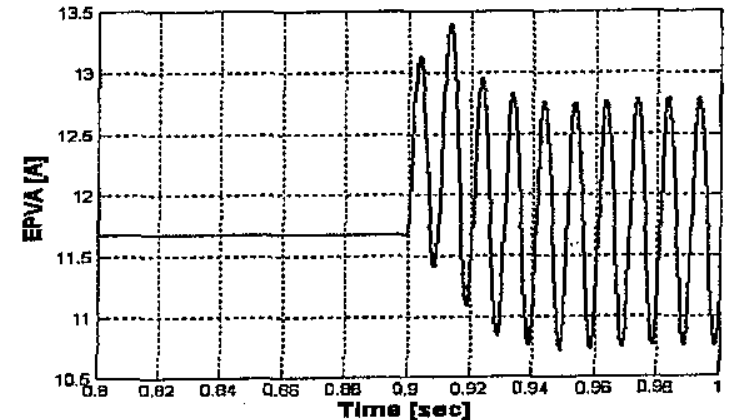

(a)

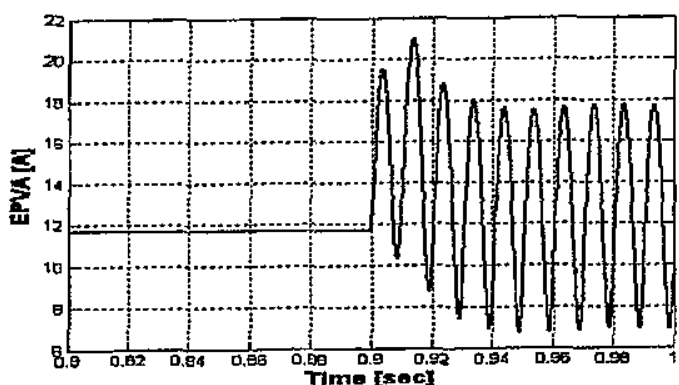

(b)

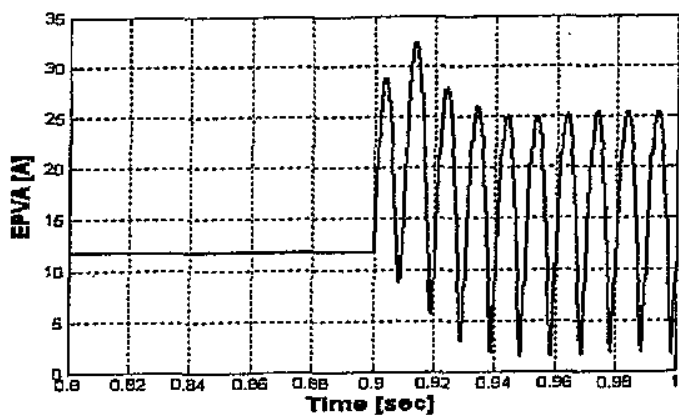

(c)

Fig. 6 Park's vector waveforms for the case of: (a) $1 \%$, (b) $5 \%$ and (c) $10 \%$ short-circuited turns.

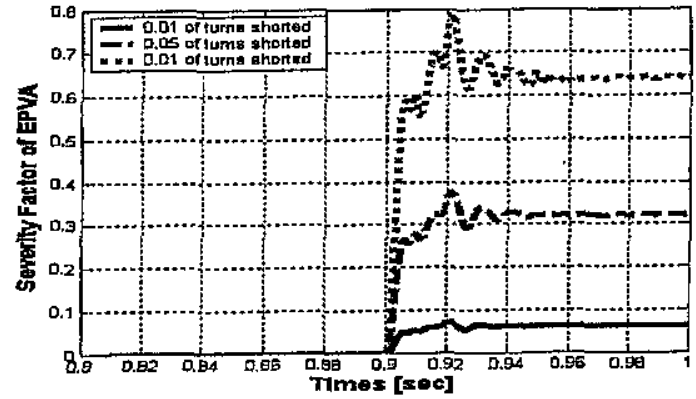

Fig. 7 Severity Factor of EPVA for the cases of: 1\%, $5 \%$ and $10 \%$ short-circuited turns.

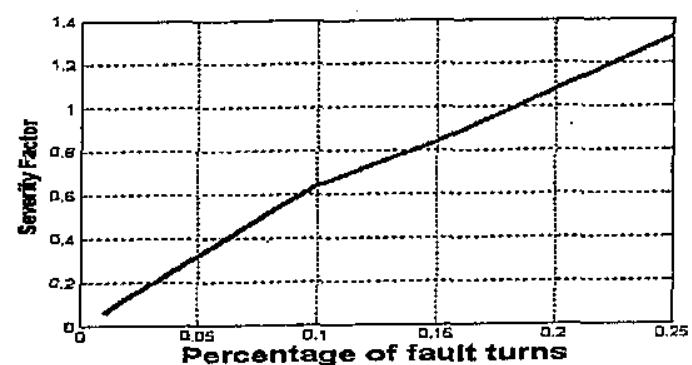

Fig. 8. The effect of turn faulted percentage and motor load on the severity factor of EPVA

\subsection{Instantaneous Input Power Technique:}

Maier in [9] describes an elegant fault-detection technique based on instantaneous input power. Multiplying the current and voltage for each phase yields the instantaneous phase power as given in the following equations:

$p_{a}=v_{a s} i_{a s} K_{s a} K_{v a}$ 


$$
\begin{aligned}
& p_{b}=v_{b s} i_{b s} K_{s b} K_{v b} \\
& p_{c}=v_{c s} i_{c s} K_{s c} K_{v c}
\end{aligned}
$$

where,

$K_{s a}, K_{s b}$, and $K_{s c}$ are unbalanced stator correction coefficients for phases $A, B$ and $C$

$K_{v a s} K_{v b}$ and $K_{v c}$ are unbalanced stator voltage correction coefficients for phases $A, B$ and $C$

$v_{a s}, v_{b s}$, and $v_{c s}$, are stator voltages of phases $A, B$ and $C$

$i_{a s,} i_{b s,}$ and $i_{c s,}$ are stator currents of phases $A, B$ and $C$

The compensated total power $p_{c c}$ is given by:

$p_{c t}=p_{a}+p_{b}+p_{c}$

which can be rewritten as:

$p_{c t}=P_{c t}(d c)+P_{c t}(a c) \cos (2 \omega t)$

where, $P_{c t}(d c)$ and $P_{c r}(a c)$ denote amplitudes of the $d c$ and ac components respectively. Let a fault indicator " $"$ " is defined as:

$\zeta=\frac{P_{c t}(a c)-P_{c t}(d c)}{P_{c t}(d c)}$

Figure. 10 shows the instantaneous input power for a $10 \%$ shorted turns. Figure. 11 illustrates the fault indicator factor for the fault cases of $1 \%, 5 \%$ and $10 \%$ short-circuited turns. Figure. 12 illustrate the change of $\zeta$ with the percentage of shorted turns.

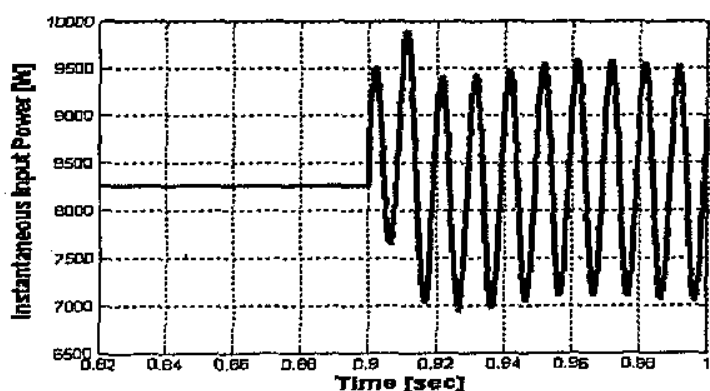

Fig. 10 Instantaneous input power for a 10\% shorted turns.

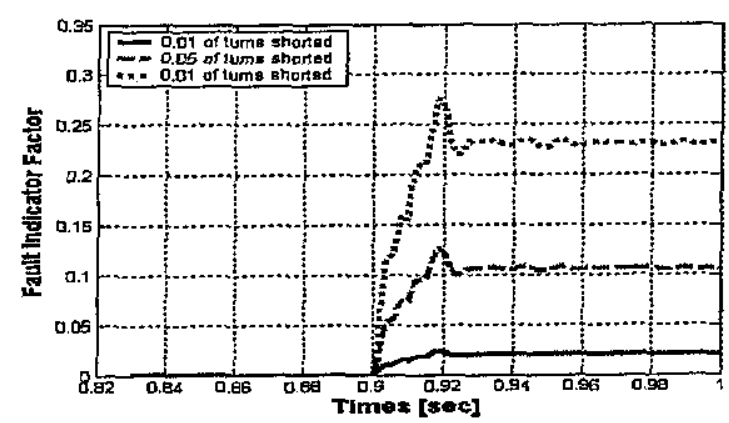

Fig. 11 Fault Indicator Factor of input power for the cases of: $1 \%, 5 \%$ and $10 \%$ short-circuited turns.

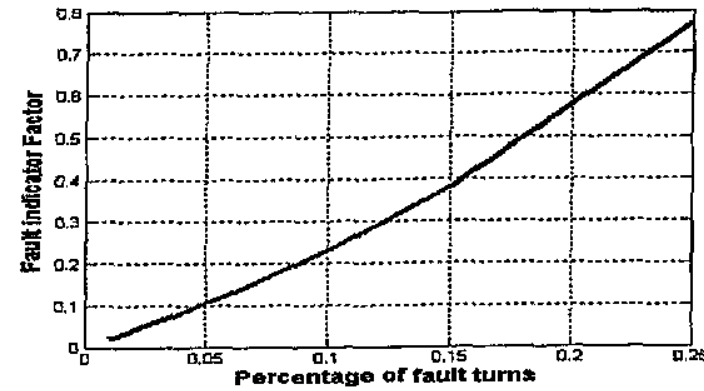

Fig. 12. The effect of turn faulted percentage and motor load on the fault indicator factor of input power

\subsection{Sequence Component Impedance Matrix Technique}

The sequence component voltage equation of a general three-phase induction motor can be expressed as:

$\left[\begin{array}{l}V_{p} \\ V_{n} \\ V_{0}\end{array}\right]=\left[\begin{array}{lll}z_{p p} & z_{p n} & z_{p 0} \\ z_{n p} & z_{n n} & z_{n 0} \\ z_{0 p} & z_{0 n} & z_{00}\end{array}\right]\left[\begin{array}{c}I_{p} \\ I_{n} \\ I_{0}\end{array}\right]$

where subscripts $p, n$ and 0 represent positive, negative and zero sequence components of the voltage and current phasors, and $z_{i j}$ represents the impedance of the $i$ sequence due to the $j$ sequence. For an ideal motor, the off-diagonal terms of the impedance matrix in equation (20), $z_{p n}, z_{p 0}, z_{n p}, z_{n 0}, z_{0 p}$ and $z_{o t}$ are zero and the sequence components are independent of each other. Due to the inherent asymmetry in the motor, the off-diagonal terms are non-zero; therefore, the sequence components are not decoupled.

From equation (20), the negative sequence voltage equation for a $Y$-connected $\left(I_{0}=0\right)$ induction motor with inherent asymmetries can be described as:

$V_{n}=z_{n p} I_{p}+z_{n n} I_{n}$

For a motor with inherent asymmetry, $z_{n p}$ is a nonzero term, that represents the degree of motor asymmetry. When a turn fault occurs in the motor, the value of $z_{n p}$ varies since the motor becomes asymmetric in a different way. Therefore, stator winding faults can be detected by continuously monitoring $z_{n p}$ and comparing it with the value of $z_{n p}$ obtained for a healthy motor, $z_{n p}{ }^{h}$, under the same slip condition. The deviation in $z_{n p}$, which is used as a turn fault indicator, is defined as:

$\Delta z_{n p}=z_{n p}-z_{n p}^{h}$

In order to calculate the value of $z_{n p}$ at a particular slip condition, two data points are required, since equation (21) contains two unknown $z_{n p}$ and $z_{n n}$. Assuming that two linearly independent sets of data 
points can be obtained as a function of slip, $z_{n p}$ can be calculated as:

$$
z_{n p}=\frac{I_{n 2} V_{n 1}-I_{n 1} V_{n 2}}{I_{p 1} I_{n 2}-I_{p 2} I_{n 1}}
$$

where subscripts 1 and 2 represent the first and the second sets of measurements.

The use of $z_{n p}$ as a turn fault indicator is immune to variation of supply voltage unbalance, since $z_{n p}$ is independent of the degree of unbalance in the supply for a fixed slip condition. This technique also does not require the motor parameters. Finally, this technique consider the imperfections in motor and measurement sensors.

Figure. 13 illustrates the change of $z_{n p}$ when a fault occurred with $1 \%$ and $10 \%$ shorted turns. The change of $z_{n p}$ with the percentage of shorted turns can be predicted as the previous methods.

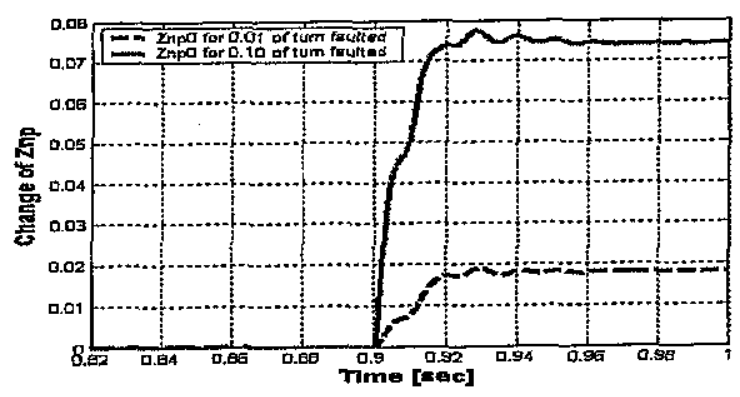

Fig. 13 Change of $z_{n p}$ for the cases of: $1 \%$ and $10 \%$ short-circuited turns.

\subsection{Positive- and Negative-Sequence Voltage Mismatch technique:}

From equation (20), $V_{n}$ can be written as:

$$
\begin{aligned}
& V_{p}=z_{p p} I_{p}+z_{p n} I_{n} \\
& V_{n}=z_{n p} I_{p}+z_{n n} I_{n}
\end{aligned}
$$

Equations(24), and (25) may be used to calculate the expected values of $V_{p}$ and $V_{n}$ at the measured motor operating speed and based on a database of $z_{p p}, z_{p n} z_{n p}$ and $z_{n n}$ constructed previously. If no internal determination has occurred, the calculated values should match the measured values $V_{p m}$ and $V_{n m}$. If internal deterioration such as a turn fault has developed, the mismatch between the measured values and the corresponding calculated values. These mismatch may then be used as a fault indicator. They are calculated as:

$$
\begin{gathered}
\Delta V_{p}=V_{p m}-\left(z_{p p} I_{p}+z_{p n} I_{n}\right) \\
\Delta V_{n}=V_{n m}-\left(z_{n p} I_{p}+z_{n n} I_{n}\right)
\end{gathered}
$$

An important advantage of this approach is that the voltage mismatch predictors should be independent of initial construction imperfections and unbalances within the motor itself. In addition, the performance of the indicator would not be affected by mismatched sensors. Therefore, no careful sensor calibration is necessary.

Figures. 14, 15 show the mismatch in positive- and negative-sequence voltage $\Delta V_{p}$, and $\Delta V_{n}$ for $1 \%, 5 \%$ and $10 \%$ shorted turns. The change of $\Delta V_{p}$, and $\Delta V_{n}$ versus turn faulted percentage is illustrated in Figure. 16.

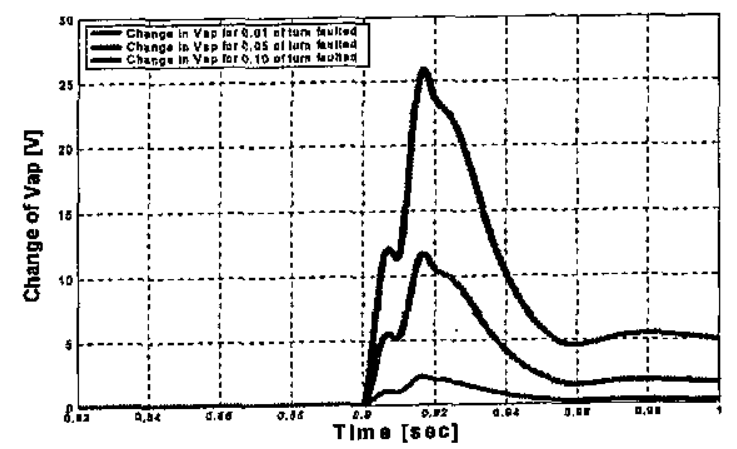

Fig. 14 The mismatch in positive-sequence voltage $\Delta V_{p}$ for $1 \%, 5 \%$ and $10 \%$ shorted turns.

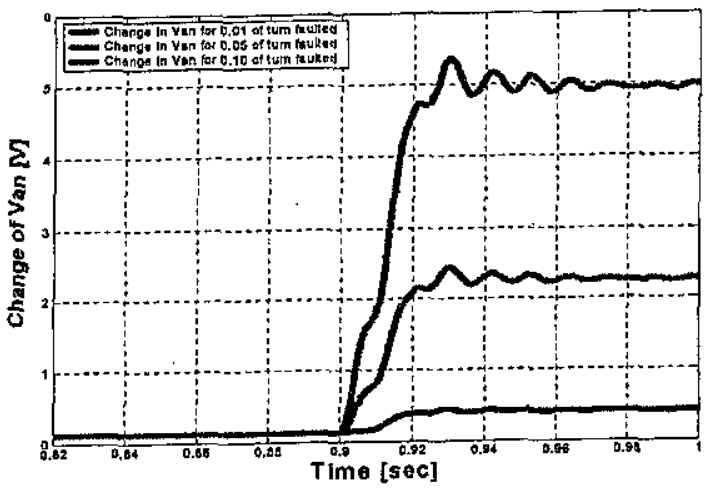

Fig. 15 The mismatch in negative-sequence voltage $\Delta V_{n}$ for $1 \%, 5 \%$ and $10 \%$ shorted turns.

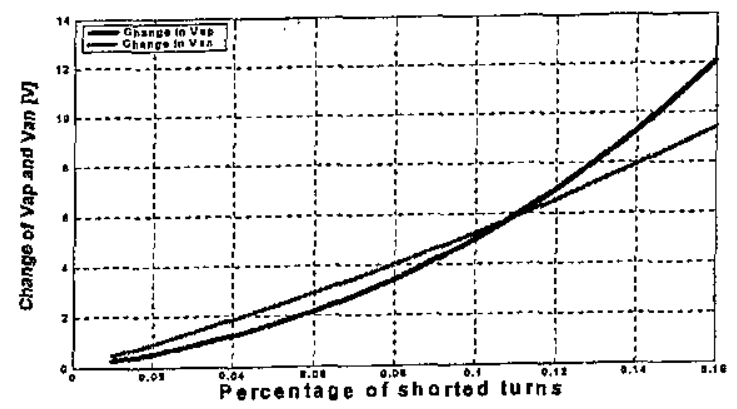

Fig. $16 \Delta V_{p}$, and $\Delta V_{n}$ Changes versus turn faulted percentage

\subsection{Proposed Neural Network Fault Detection System}

The NN structures used in the diagnostics are of the multilayer perceptron type, trained using the backpropagation algorithm. The proposed net structure of a single hidden layer is shown in Figure. 
17. The input vectors are the stator voltage and current magnitude. Training a network by backpropagation involves three stages: the feedforward of the input training pattern, the backpropagation of the associated error, and the adjustment of the weights. During the learning process, the NN weights are adapted in order to create the desired output vectors. For learning process, the symptom-fault map is required. There is also the possibility of a hybrid learning process, simulated data for healthy and faulty machines. In this way, the NN can learn the health condition

The faulty machine signal is generated by the model as described in section II. The time domain signais both healthy and faulty machines are passed through the low pass filter. Then the time domain signal is changed to frequency domain by Fourier transform. The magnitude from DFT is used to compute the input vector for training the NN which defines the target as healthy or faulty. After training NN, we have the weight and bias for using to detect the faulty machine.

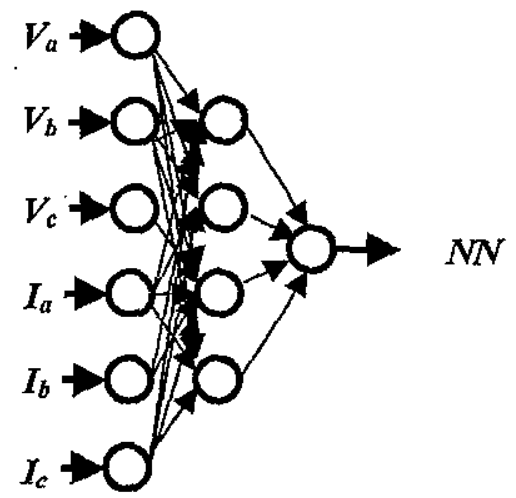

Fig. 17. The proposed net structure of a single hidden layer

Figure. 18 illustrate the response of the network for a case involving fault occurs at $0.9 \mathrm{sec}$. The percentage of faulty turns is 0.01 .

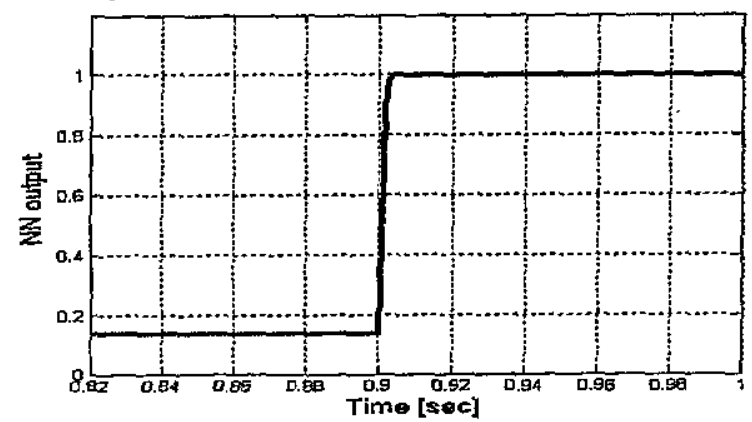

Fig. 18. The output of the proposed NN

\section{COMPARISON OF THE RESULTS}

The following Figures show the response of various fault detection method under certain abnormal conditions such as unbalance in the input voltage, inherent asymmetries between the phases of the motor, and a stator winding turn short-circuit. Figure.19 illustrates the response of conventional five approaches for $5 \%$ unbalance in the phase a. The response of these approaches against $1 \%$ shorted turns in phase a is illistrated in Figure. 20.

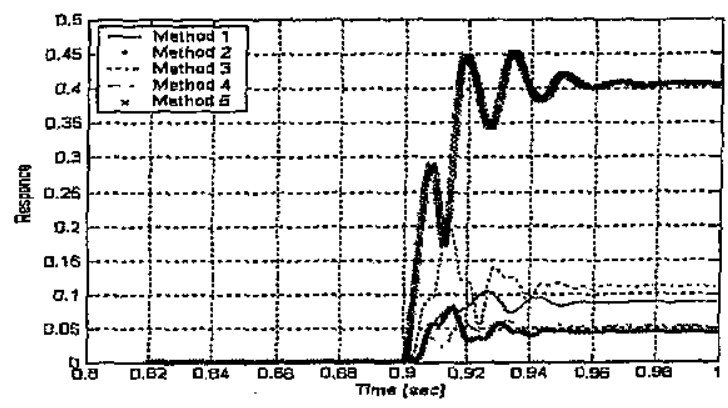

Fig. 19. The output response of five approaches for $5 \%$ unbalance in the phase a

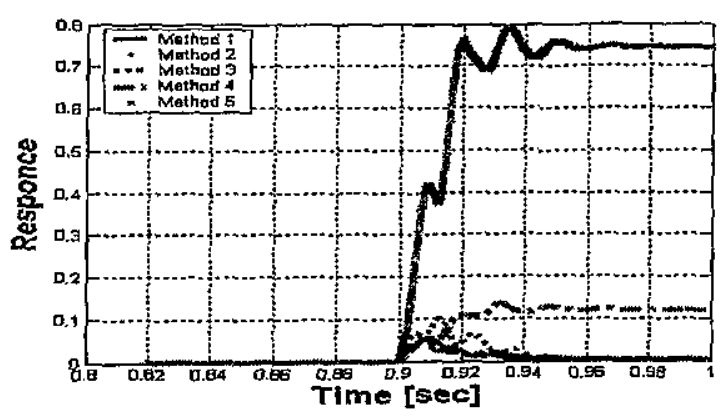

Fig. 20. The output response of five approaches for $1 \%$ shorted turns in phase a

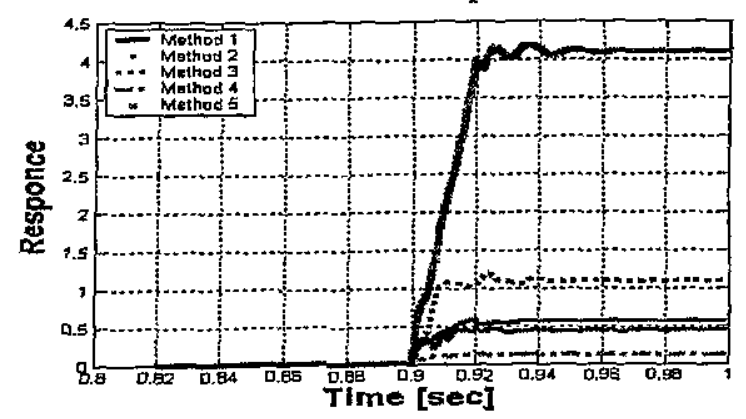

Fig. 21. The output response of five approaches for $10 \%$ shorted turns in phase a

From these figures, it can be seen that in the first, second and third methods fault detector response is increased with any disturbance and reaches to its steady value after about $0.04 \mathrm{sec}$ from the disturbance occurrence. However, the response for the fourth and fifth methods needs about $0.06 \mathrm{sec}$ to reach its steady value. The response of all techniques are affected by the voltage unbalance. In the first four methods a steady value of the response does not increase 0.1. The fifth method response reaches a 0.45 and 0.8 for unbalance voltage and shorted turns respectively. 


\section{CONCLUSION}

A comparative study among five fault detection methods, used for induction motor stator winding turn fault, has been presented. The results have shown that with the first three methods considered, the imperfections in motor and the supply unbalance have a huge effect on the indicator. The location of fault "percentage of shorted turns" has a substantial effect on increasing the visibility of fault signature. The last two methods depending on the sequence components have a good indication for fault occurring. These methods need not motor parameters and are not affected by motor imperfections. In all five methods a steady output from the fault detector is obtained in about $40 \mathrm{msec}$ from the instant of fault occurrence. All of these advantages and more may be collected using the proposed NN-based method.

\section{APPENDIX}

$\begin{array}{ll}\text { Rated stator voltage per phase } \mathrm{V}_{s}: & 220 \mathrm{~V} \\ \text { Stator connection: } & \mathrm{Y} \\ \text { Stator resistance Rs: } & 0.435 \Omega \\ \text { Rotor resistance Rr: } & 0.816 \Omega \\ \text { Stator leakage inductance ILls: } & 2.4 \mathrm{mH} \\ \text { Rotor leakage inductance Llr: } & 2.4 \mathrm{mH} \\ \text { Magnetizing inductance Lm: } & 83.17 \mathrm{mH} \\ \text { Moment of inertia constant J: } & 0.089 \mathrm{~kg} \cdot \mathrm{m}^{2} \\ \text { Rated output power: } & 3 \mathrm{hp}\end{array}$

\section{REFERENCES}

[1] Motor Reliability Working Group, "Report of large motor reliability survey of industrial and commercial installations Part I, and II," IEEE Trans. Ind. Appl, vol. IA-21, no. 4, pp. 853-872, Jul./Aug. 1985.

[2] A. H. Bonnett and G. C. Soukup, "Rotor failures in squirrel cage induction motors," IEEE Trans. Ind. Appl, vol. IA-22, no. 6, pp. 1165-1173, Nov./Dec. 1986.

[3] R. R. Schoen, T. G. Habetler, F. Kamran, and R. G. Bartheld, "Motor bearing damage detection using stator current monitoring," IEEE Trans.
Ind. Appl., vol. 31, no. 6, pp. 1274-1279, Nov./Dec. 1995.

[4] P.F. Albrecht, J.C. Appiarius, and D.K. Sharma, "Assessment of the reliability of motors in utility applications-Updated," IEEE Transactions on Energy Conversion, vol.1, pp.39-46, December 1986.

[5] A. H. Bonnett, G. C. Soukup, "Cause and analysis of stator and rotor failures in three-phase squirrelcage induction motors," IEEE Transactions on Industry Applications, vol. 28, no. 4 July/August 1992, pp 921-937.

[6] L. Manz, "Motor insulation system quality for IGBT drives," IEEE Industry Applications Magazine, vol. 3, no. 1, January/February 1997, pp 51-55.

[7] W. McDermid, "Insulation systems and monitoring for stator windings of large rotating machines," IEEE Electrical Insulation Magazine, vol. 9, no. 4, July/August 1993, pp 116-121

[8] M. A. Cash, "Detection of turn faults arising from insulation failure in the stator windings of $\mathrm{AC}$ machines," $\mathrm{Ph} \mathrm{d}$ thesis presented to the academic faculty, June 1998.

[9] Reinhard Maier, "Protection of Squirrel-Cage Induction Motor Utilizing Instantaneous Power and Phase Information," IEEE Trans. Ind. Appl., vol. 32, no. 4, pp. 904-909, Jul./Aug. 1996.

[10] S. Williamson and P. Mirzoian, "Analysis of cage induction motor with stator winding faults," IEEE Trans. Energy Convers., vol. 10, no. 2, pp. 241-247, Jun. 1985.

[11] C. Xianrong, V. Cacquempot, and C. Christophe, "A model of asynchronous machines for stator fault detection and isolation," IEEE Trans.Ind. Electron., vol. 50, no. 3, pp. 578-584, Jun. 2003.

[12] Murty V.V.S.Yalla," A Digital Multifunction Protective Relay," IEEE Transactions on Power Delivery, Vol. 7, No. 1, January 1992, pp. 193200. 